\title{
As edicións facsimilares no Castro, un exemplo de recuperación da memoria histórica
}

\author{
Facsimile Editions in O Castro, an Example of Recovering \\ Historical Memory
}

\section{Leticia Quintás PÉRez}

Universidade da Coruña

Departamento de Galego-Portugués, Francés e Lingüística

leticia.quintas.perez@udc.es

[recibido 30/10/2014, aceptado 08/02/2015]

\section{RESUMO}

Ediciós do Castro nace no ano 1963 co obxectivo principal de recuperar a memoria histórica da Galiza, silenciada durante os anos do franquismo. O presente traballo estuda unha parte da produción desta editorial, as edicións facsimilares, tendo en conta, en primeiro lugar, a súa descrición para, a seguir, facer unha análise e unha posterior valoración do que estas supuxeron no panorama editorial da época.

PALABRAS CHave: Memoria histórica, edicións facsimilares, Ediciós do Castro, Díaz Pardo, exilio, represión.

\section{RESUMEN}

Ediciós do Castro nace en el año 1963 con el objetivo principal de recuperar la memoria histórica de Galiza, silenciada durante los años del franquismo. El presente trabajo estudia una parte de la producción de esta editorial, las ediciones facsimilares, teniendo en cuenta, en primer lugar, su descripción para, a continuación, hacer un análisis y una posterior valoración de lo que estas supusieron en el panorama editorial de la época.

PALABRas ClaVe: Memoria histórica, ediciones facsimilares, Ediciós do Castro, Díaz Pardo, exilio, represión.

\section{ABSTRACT}

The publishing house Edicións do Castro was founded in 1963 with the aim of recovering Galicia's historical memory, silenced during the years of the Franco regime. The present paper studies a part of the production of this publishing house, namely facsimile editions. It first focuses on their description and then carries out an analysis and subsequent evaluation of the relevance of these facsimile editions within the publishing scenario of the period.

KEY WORDS: Historical memory, facsimile editions, Ediciós do Castro, Díaz Pardo, exile, repression.

Quintás PÉREZ, L. (2015): “As edicións facsimilares no Castro, un exemplo de recuperación da memoria histórica”, Madrygal (Madr.), 18, Núm. Especial: 517-528.

SUMARIO: 1. Introdución. 2. Publicacións facsimilares no Castro. 3. Primeiras edicións. 3.1. O exilio, os exiliados e a loita contra o franquismo. 3.2. Recuperación de textos literarios de autores clásicos. 3.3. Materiais científicos de valor histórico. 3.4. Outras publicacións facsimilares. 4. Valoracións e conclusións. 5. Referencias bibliográficas. 


\section{INTRODUCIÓN}

Non resulta inadecuado lembrar que Ediciós do Castro forma parte dun dos núcleos empresariais máis recoñecidos na Galiza, creado por Isaac Díaz Pardo a mediados do século XX. Este iníciase coa posta en marcha dunha empresa centrada na produción de cerámica ${ }^{1}$ á que lle seguirán a Fábrica de Cerámicas da Magdalena, o Museo Carlos Maside, Sargadelos, ou mesmo as Ediciós do Castro. En 1963 nace unha institución que recolle as ideas que Díaz Pardo, xunto a Luís Seoane, puxeron sobre a mesa na Arxentina, coa pretensión de facer algo pola Galiza e polo pobo que loitara durante tres anos na guerra civil (1936-1939). O que pretendían era recuperar a memoria que quedara silenciada ou agochada por medo a unha posíbel represión contra os que intentasen reconstruír a historia ${ }^{2}$. Aparece, así, o Laboratorio de Formas, que tiña como obxectivo incidir en tres campos diferentes: a comunicación, a industria e a cultura ${ }^{3}$. Para iso, elabora un triplo proxecto co que inicia a súa andaina: en 1963 crea unha editorial que leva por nome Ediciós do Castro, en 1968 inicia a restauración de Sargadelos en Cervo (Lugo) e, finalmente, en 1970 pon en marcha o Museo Carlos Maside.

Antes de comezar o noso traballo, debemos sinalar a escasa atención crítica con que foi recibida a editora desde a data da súa creación até a actualidade, feito que nos leva a considerar de grande interese a reflexión sobre un determinado conxunto de obras que forman parte da súa produción. A empresa creada por Díaz Pardo conta con aproximadamente 1500 títulos distribuídos ao longo de coleccións que abranguen desde temas científicos até escrita de creación en todos os xéneros. O obxectivo principal que pretendemos acadar consiste en analizar o número de facsimilares que desde moi cedo aparecen na editorial e valorar os motivos polos que pensamos que isto é levado a cabo. O noso primeiro paso será describir os materiais tendo en conta a forma en que aparecen publicados no Castro para, a continuación, ver como eran os textos orixinais e poder afondar no noso estudo.

\section{PUBLICACIÓNS FACSIMILARES NO CASTRO}

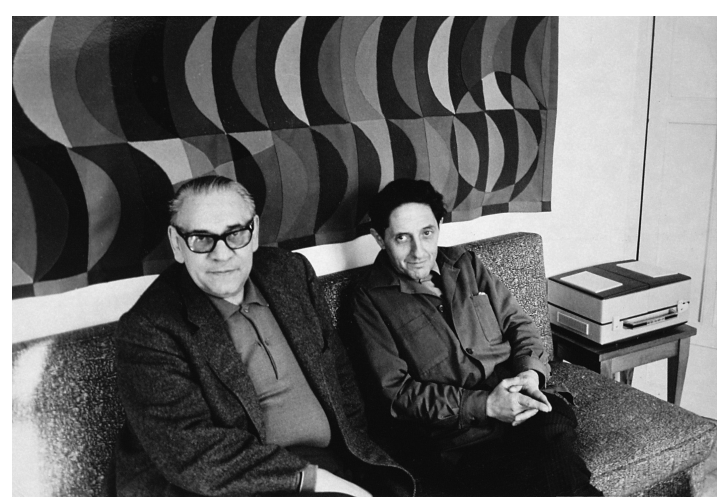

Se nos detemos no amplo catálogo publicado por Ediciós do Castro, decatámonos de que existen un total de 48 edicións facsimilares publicadas entre os anos 1972 e 2008 e distribuídas ao longo de diferentes coleccións. Deste modo, destacan sobre as demais as elaboradas polas Áreas do Seminario de Estudos Galegos, que se centran na recuperación dunha memoria científica, e as da colección "Documentos para a historia de Galicia", que naceu co afán de retomar o noso pasado esquecido;

\footnotetext{
${ }^{1}$ Cando Isaac reside en Madrid, le un libro de Bello Piñeiro no que se fai referencia á fábrica de Sargadelos (creada por Antonio Raimundo Ibáñez no século XIX) e á forma en que esta perdeu os seus caolíns; e chega, deste modo, a convencerse de que é necesario restaurar todo aquilo.

${ }^{2}$ Isaac Díaz Pardo comenta nunha das súas entrevistas: "Seoane tiña claro que había que actuar aquí, no país, no marco de posibilidades que a nova fase da ditadura permitía, e que debiamos facelo dende a independencia da empresa privada, conxugando a iniciativa empresarial e económica coa produción cultural ó servicio da identidade e a reconstrución do país. Non hai proxecto empresarial sen compromiso. O noso compromiso, dende o principio, foi contribuír ó proceso de recuperación da memoria e da dignidade de Galicia, segundo o que os devanceiros nos ensinaron" (Freixanes 2003: 71).

${ }^{3}$ Para máis información sobre o Laboratorio de Formas, véxase Laboratorio de Formas de Galicia (1970), Soneira Beloso (2007) e Díaz (2008).
} 


\begin{tabular}{|c|c|}
\hline \multicolumn{2}{|r|}{ Publicacións facsimilares feitas polo Castro } \\
\hline \multicolumn{2}{|r|}{ Xornais } \\
\hline 1988 & Galicia. Vigo 1922-1925 \\
\hline 2000 & Reprodución facsimilar do xornal El barbero municipal. Rianjo 1910-1914 \\
\hline \multicolumn{2}{|r|}{ Revistas } \\
\hline 1987 & Viajes de herborización por Galicia, Baltasar Merino \\
\hline 1990 & Nova Galiza \\
\hline 1994 & $\begin{array}{l}\text { Correo literario } \\
\text { Galicia emigrante }\end{array}$ \\
\hline 1995 & P.A.N. Revista espistolar y de ensayos \\
\hline 1997 & Nueva Galicia \\
\hline \multicolumn{2}{|r|}{ Libros } \\
\hline 1972 & Jacobusland, Emilio Pita \\
\hline 1978 & Terra de Melide, Seminario de Estudos Galegos \\
\hline 1982 & $\begin{array}{l}\text { Curso práctico de apicultura, Benigno Ledo González } \\
\text { Grabados en linoleum, Xaime Prada } \\
\text { Santa Marta de Moreiras, Xosé Ramón e Fernández Oxea }\end{array}$ \\
\hline 1983 & Ensayo de una historia de los peces, Joseph A. Cornide Saavedra \\
\hline 1985 & $\begin{array}{l}\text { Descripción geonóstica del reino de Galicia, Guillermo Schulz } \\
\text { Reformas que se pueden implantar en Galicia para el progreso de la agricultura, Juan Rof Codina }\end{array}$ \\
\hline 1986 & Os calaicos. Odas de Anacreonte, Florencio Vaamonde Lores \\
\hline 1987 & $\begin{array}{l}\text { Memoria sobre el conocimiento de las tierras, Francisco Cónsul Jove i Tineo } \\
\text { Tres tempos y la esperanza, } M^{a} \text { Victoria Valenzuela Otero }\end{array}$ \\
\hline 1988 & Enumeración de los curculiónidos de pa Península Ibérica e Islas Baleares, Luís Iglesias Iglesias \\
\hline 1989 & $\begin{array}{l}\text { Compendio de Albeytaría, Fernando de Sande y Lago } \\
\text { Homenaje a la Torre de Hércules, Luís Seoane }\end{array}$ \\
\hline 1991 & $\begin{array}{l}\text { Cuaderno de campo, Guillermo Schulz } \\
\text { Primer congreso de economía gallega } \\
\text { Soledad imposible, Arturo Cuadrado }\end{array}$ \\
\hline 1992 & $\begin{array}{l}\text { Historia del periodismo santiagués, Pablo Pérez Constanti } \\
\text { La cuna gallega de Cristóbal Colón, José M. Mosqueira Manso } \\
\text { Tres en uno. Auto sacramental a la usanza antigua, Juan Bartolomé de Roxas }\end{array}$ \\
\hline 1993 & $\begin{array}{l}\text { Beira o Barbaña. Paisaxes, Francisco Álvarez de Nóvoa } \\
\text { Pelerinaxes I, Ramón Otero Pedrayo }\end{array}$ \\
\hline 1994 & Congreso agrícola gallego de 1864 \\
\hline 1995 & $\begin{array}{l}\text { El último pirata del mediterráneo, Manuel D. Benavides } \\
\text { La pell de Brau, Salvador Espriu } \\
\text { La Universidad de Santiago. El pasado y el presente, Ciriaco Pérez Bustamante e Sebastián González García-Paz }\end{array}$ \\
\hline 1996 & $\begin{array}{l}\text { Cancioneiro da loita galega } \\
\text { La novela del indio Tupinamba, Eugenio Fernández Granell } \\
\text { Reseña de la historia natural de Galicia, López Seoane } \\
\text { Tres hojas de ruda y un ajo verde o las narraciones de un vagabundo, Luís Seoane }\end{array}$ \\
\hline 1997 & Eduardo Chao. Estudio biográfico-político, Manuel Curros Enríquez \\
\hline 1998 & Declaración Universal dos dereitos do home \\
\hline 2000 & Corpus petroglyphorum gallaeciae, Ramón Sobrino Buhigas \\
\hline 2001 & $\begin{array}{l}\text { Os tres poemas premiados en } 1887 \text { no certame de Ourense, Manuel Curros Enríquez } \\
\text { Ritmo y abstracción y los procesos abstractivos del arte contemporáneo, Tomás Barros }\end{array}$ \\
\hline 2003 & Prisión central. Celanova (1939-1940) \\
\hline 2004 & Catro poemas gallegos, Lorenzo Varela \\
\hline 2005 & $\begin{array}{l}\text { Arlequinada, Torcuato Ulloa Varela } \\
\text { Lonxe, Lorenzo Varela }\end{array}$ \\
\hline 2008 & Galicia hoy \\
\hline
\end{tabular}

Tabela 1 
mais estas non son as únicas coleccións en que o Castro introduce edicións facsimilares ${ }^{4}$. Entre os tipos de publicacións contamos con dous xornais, seis revistas e corenta libros onde podemos distinguir, por un lado, textos poéticos, narrativos ou teatrais e, por outro, textos de carácter ensaístico, publicacións derivadas de congresos, textos científicos ou obras de creación artística. Na Tabela 1 recóllense ordenadas de forma cronolóxica as obras que, ao longo da historia da editora, apareceron como edicións facsimilares.

Practicamente, todas estas publicacións contan cun prólogo ou limiar cuxa función é explicar o motivo polo cal se decide recuperar a obra. Alén diso, estas introducións, feitas en páxinas amarelas, son as encargadas de nos situar no momento histórico da creación do orixinal para amosar o interese da súa recuperación e, en ocasións, ocúpanse de nos dar a coñecer o seu autor co obxectivo de lle render unha homenaxe. No caso das revistas e xornais, os prólogos sitúanas nun contexto histórico e social concreto que amosa cal era a situación que se estaba a vivir no lugar onde se publican, cantos números se realizan e cal era o custo destes. Entre os encargados de prologar estas edicións que hoxe recollemos aquí, encontramos nomes como Xesús Alonso Montero, Xosé Luís Axeitos, Isaac Díaz Pardo ou Francisco Fernández del Riego, que no seu momento estudaron e recuperaron unha parte da historia que eses textos ofrecían. Por último, e para coñecermos de forma aproximada os exemplares elaborados na editora, resulta pertinente facer referencia ao número de vendas destes exemplares. As tiraxes feitas deste tipo de reproducións sitúanse entre as 400 e as 1000, sendo o Curso práctico de apicultura e El último pirata del mediterráneo as que teñen máis edicións (catro cada unha), seguidas da Descripción geognóstica del reino de Galicia e do Homenaje a la torre de Hércules (dúas edicións). Isto deixa ver o interese por unhas obras cuxa finalidade parecía quedar relegada ao esquecemento.

\section{PRIMEIRAS EDICIÓNS}

Ediciós do Castro, a través dos facsimilares, achéganos a unha época actual obras cuxas primeiras edicións foron publicadas entre o século XVIII e o século XX. Deste xeito, e como observamos no seguinte cadro, podemos facer unha división entre aquelas obras que aparecen por primeira vez nos anos anteriores ao século $\mathrm{XX}$ e as que foron publicadas nese século. Ademais, dentro destas últimas, e como consecuencia dos acontecementos sociais e políticos que teñen lugar no país, resulta necesario diferenciar entre as obras que saíron á luz no momento previo á guerra civil, as publicacións feitas durante o réxime franquista, aquelas outras cuxa edición aparece por primeira vez en América e as que se publican noutros lugares europeos (Tabela 2).

Todos estes materiais orixinais aos que nos acabamos de referir foron publicados en lugares diferentes: na Galiza, en América, en cidades españolas ou en cidades de Europa, dependendo da situación social de cada momento. Se nos detemos nos lugares de edición destas publicacións, dentro do territorio galego sobresaen as principais cidades galegas, entre as que se encontran A Coruña, Lugo, Ourense, Pontevedra, Vilagarcía, Vigo ou Santiago, que contan con editoras como Castrelos, Imprenta Carré, Imprenta Roel, Imprenta de Soto Freire ou mesmo a Universidade de Santiago, cuxa función é introducir certas publicacións no sistema literario galego do momento.

Outras obras, pola súa banda, aparecen nalgunhas cidades españolas (como é o caso de Madrid e Barcelona), especialmente aquelas que pertencen ao século XVIII e as revistas que xorden a comezos do século XX. Debemos referirnos, así mesmo, ao destacado papel que se leva a cabo en América especialmente nas cidades de Buenos Aires, México ou La Habana da man de editoras como Botella al Mar, Citania, Nova, Alborada, Ediciones Roca ou mesmo o Partido Galeguista. Por último,

\footnotetext{
4 Tamén aparecen edicións facsimilares nas coleccións de "Historia", "Poesía", "Arte", "Narrativa" e nunha serie de publicacións varias centradas, principalmente, en textos de carácter xornalístico.
} 


\begin{tabular}{|c|c|c|}
\hline \multicolumn{3}{|r|}{ Publicacións das primeiras edicións } \\
\hline & Século XVIII & $\begin{array}{l}\text { Compendio de Albeytería (1729) } \\
\text { Memoria sobre el conocimiento de las tierras (1786) } \\
\text { Ensayo de una historia de los peces (1788) }\end{array}$ \\
\hline 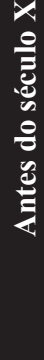 & Século XIX & $\begin{array}{l}\text { Cuaderno de campo (1832) } \\
\text { Descripción geognóstica del reino de Galicia (1835) } \\
\text { Congreso agrícola gallego de } 1864 \text { (1864) } \\
\text { Reseña de la historia natural de Galicia (1866) } \\
\text { Os tres poemas premiados en } 1877 \text { no certame de Ourense (1877) } \\
\text { Beira o Barbaña. Paisaxes (1884) } \\
\text { Eduardo Chao. Estudio biográfico-político (1893) } \\
\text { Arlequinada (1894) } \\
\text { Os calaicos. Odas de Anacreonte (1897) }\end{array}$ \\
\hline \multirow{4}{*}{ 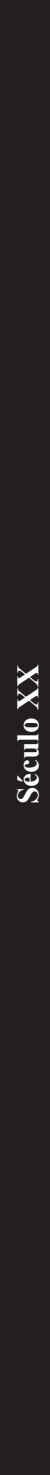 } & $\begin{array}{c}\text { Preguerra } \\
\text { (antes de 1936) }\end{array}$ & $\begin{array}{l}\text { Viajes de herborización por Galicia (1901) } \\
\text { Historia del periodismo santiagués (1905) } \\
\text { Reproducción facsimilar do xornal El barbero municipal. Rianjo. 1910-1914 (1910) } \\
\text { Reformas que se pueden implantar en Galicia para el progreso de la agricultura (1912) } \\
\text { Enumeración de los curculiónidos de la Península Ibérica e Islas Baleares (1920) } \\
\text { Galicia. Vigo 1922-1925 (1922) } \\
\text { Primer congreso de economía gallega (1926) } \\
\text { Grabados en linoleum (1927) } \\
\text { Pelerinaxes I (1929) } \\
\text { Terra de Melide (1933) } \\
\text { La universidad de Santiago. El pasado y el presente (1934) } \\
\text { Corpus petroglyphorum gallaeciae (1935) } \\
\text { P.A.N. Revista epistolar y de ensayos (1935) }\end{array}$ \\
\hline & $\begin{array}{c}\text { Guerra e } \\
\text { posguerra } \\
(1936-1976)\end{array}$ & $\begin{array}{l}\text { Nova Galiza }(1937) \\
\text { Nueva Galicia }(1937) \\
\text { Prisión central. Celanova (1939-1940) (1939) } \\
\text { Curso práctico de apicultura }\left(3^{\mathrm{a}} \mathrm{ed} .1936\right) \\
\text { Ritmo y abstracción y los procesos abstractivos del arte contemporáneo (1965) } \\
\text { Santa Marta de Moreiras (1968) } \\
\text { Declaración Universal dos dereitos do home (1968) }\end{array}$ \\
\hline & $\begin{array}{c}\text { Exilio } \\
\text { (América) }\end{array}$ & $\begin{array}{l}\text { Soledad imposible (1936) } \\
\text { Tres en uno. Auto sacramental a la usanza antigua (1940) } \\
\text { Jacobusland (1942) } \\
\text { Cancioneiro da loita galega (1943) } \\
\text { Correo literario (1943) } \\
\text { Homenaje a la torre de Hércules (1944) } \\
\text { Tres hojas de ruda y un ajo verde o las narraciones de un vagabundo (1948) } \\
\text { Catro poemas galegos (1951) } \\
\text { Galicia emigrante (1954) } \\
\text { Lonxe (1954) } \\
\text { La novela del indio Tupinamba (1959) } \\
\text { La cuna gallega de Cristóbal Colón (1961) } \\
\text { Tres tiempos y la esperanza (1962) } \\
\text { Galicia hoy (1966) } \\
\text { El último pirata del mediterráneo (1976) }\end{array}$ \\
\hline & Outros & La pell de Brau (1963) \\
\hline
\end{tabular}

Tabela 2 
existiron outros lugares de publicación dentro do continente europeo como é o caso de $\mathrm{Pa}$ rís, onde xorde a editora Ruedo Ibérico, que se encargaba de dar a coñecer certos materiais que a censura impedía publicar en España.

Se volvemos ao conxunto de publicacións que o Castro reedita, resulta pertinente facermos unha proposta de clasificación atendendo aos temas que se recollen ${ }^{5}$, como son: o exilio, os exiliados e a loita contra o franquismo, a recuperación de textos literarios de autores clásicos e a publicación daqueles materiais científicos de valor histórico que nos serven para facer unha análise da realidade sociocultural galega.

\subsection{O EXILIO, OS EXILIADOS E A LOITA CONTRA O FRANQUISMO}

Esta liña foi adquirindo unha importancia moi grande dentro do conxunto editorial, como demostra, entre outras cousas, a colección Documentos para a historia de Galicia ${ }^{6}$, na que se evidencia a necesidade de contar a historia. Para facelo, era necesaria a colaboración de testemuñas que coñecesen en primeira persoa a situación que a moitos galegos e galegas lles tocou vivir. No caso das edicións facsimilares, poderiamos agrupar aquí todas as obras que apareceron en América nos anos posteriores á guerra civil, que foron asumidas por un grupo de galegos que non quixo consentir as agresións polas que estaba a pasar a nosa cultura, e que decide publicar na Galiza exterior dando lugar a unha importante actividade cultural ao outro lado do Atlántico. Este é o caso de obras como Jacobusland de Emilio Pita, publicada en Buenos Aires en 1942 por este poeta emigrado, onde destaca unha vocación de continuidade co feito antes da guerra na Galiza, ou de Catro poemas gallegos e Lonxe, ambas as dúas de Lorenzo Varela, publicadas tamén en Buenos Aires en 1951 e 1954, respectivamente, e en cuxo interior se recollen debuxos de Seoane que acompañan o texto e lle conceden moita importancia ao pobo galego e á situación pola que está a pasar naqueles anos en que as consecuencias da guerra estaban moi presentes.

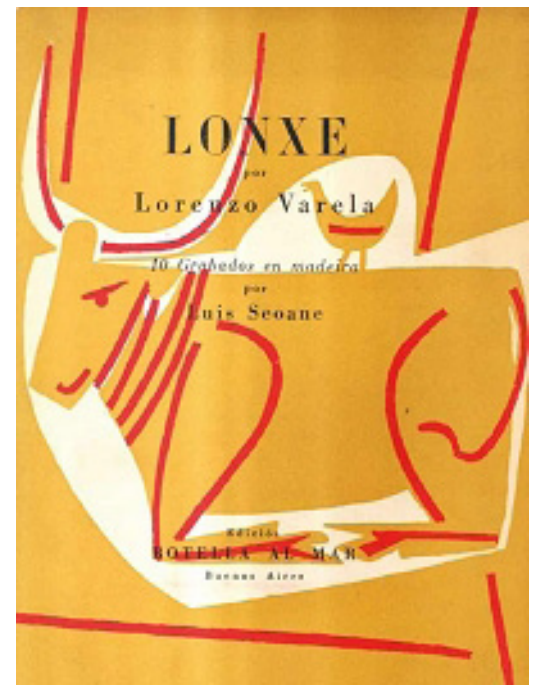

Do mesmo xeito e continuando con esta liña, existe unha serie de obras que tiveron que ser editadas no continente americano por non conseguir ser publicadas na Galiza daquel tempo. Exemplos deste tipo son El último pirata del Mediterráneo de Manuel Benavides, Tres en uno. Auto sacramental a la antigua usanza de Bartolomé de Roxas, Soledad imposible de Arturo Cuadrado ou La cuna gallega

${ }^{5}$ Debemos aclarar que, en moitos dos casos, imos atopar algúns títulos que poderían pertencer a diferentes agrupacións temáticas, xa que non é só un motivo de interese o que conteñen, nin un único tema a tratar.

${ }^{6} \mathrm{Na}$ lapela do primeiro número desta colección aparece xa a súa finalidade: "Baixo ese titular [“Documentos para a historia contemporánea de Galicia"] EDICIÓs DO CASTRO inicia unha colección coa intención de contribuír á divulgación de testemuñas que podan axudar a facer unha aproximación á historia contemporánea de Galicia. As circunstancias que atraparon á nosa terra no ano 1936 fan difícil esta tarea. Pro sería mala cousa que en función de razóns alleas á historia, aínda que valiosas dende algún punto de convivencia, o noso acontecer recente fose sileciado, borrado ou desfigurado; porque temos a seguranza de que o futuro vai ficar lastrado das mesmas chatas que sufra a memoria" (Cores Trasmonte 1981). 
de Cristóbal Colón de José M. Mosqueira Manso. Dentro deste grupo, podemos incluír, tamén, a obra de Luís Seoane Tres hojas de ruda y un ajo verde o las narraciones de un vagabundo, que apareceu publicada por primeira vez en Botella al mar, en Buenos Aires en 1948, e que reúne unha serie de narracións con referencias ao mundo medieval que serven para nos achegar a un pasado que nos identifique como pobo. Alén diso, Luís Seoane publica no exilio Homenaje a la Torre de Hércules, un libro de carácter artístico que comentaremos máis adiante.

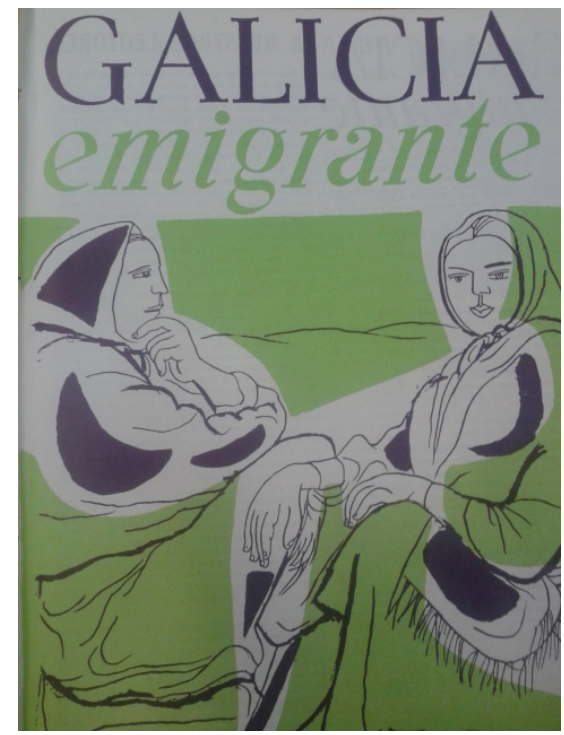

Por último, debémonos referir a aquelas obras cuxo interese reside no seu contido, relacionado coa loita antifranquista e coa denuncia da situación pola que pasaba Galiza durante os primeiros anos da ditadura. Son exemplos disto o Cancioneiro da loita gallega, feito polo Partido Galeguista, que recolle poemas patrióticos, sociais e de denuncia; La novela del indio Tupinamba de Eugenio Fernández Granell, onde se relata a guerra civil e as súas consecuencias; Tres tiempos y la esperanza de $\mathrm{M}^{\mathrm{a}}$ Victoria Valenzuela, en que unha biografía da autora serve para nos achegar unha situación de persecución, tiranía e desesperanza, e La pell de Brau de Salvador Espriu, publicada por Ruedo Ibérico en París e que contén un poema que desenvolve, novamente, o tema da guerra civil e a resonancia social que esta tivo.
Tamén incluímos neste grupo Galicia hoy, volume clandestino durante a última época de Franco que contén unha serie de documentos e textos antifranquistas cuxa distribución non se logrou impedir.

Existiron, tamén, en América, unha serie de publicacións de carácter divulgativo como son as revistas Correo Literario e Galicia emigrante que foron feitas polos galegos que fuxían da barbarie fascista para continuar coa difusión da cultura galega ao outro lado do Atlántico, mentres esperaban a que a situación na Galiza se suavizase. Correo Literario estivo dirixida por un grupo de exiliados galegos, Arturo Cuadrado, Luís Seoane e Lorenzo Varela, e apareceu en Buenos Aires cunha periodicidade quincenal entre os anos 1943 e 1945. Aínda que non era unha revista para un público galego, como ocorrerá con Galicia emigrante, tiña como obxectivo principal dar a coñecer algunhas manifestacións culturais de Galicia en Latinoamérica. No segundo dos casos, Galicia emigrante apareceu en 1943 da man de Luís Seoane e José Antonio Fernández co propósito de tratar a emigración e os seus problemas e achegar Galiza á xente de alén mar.

\subsection{RECUPERACIÓN DE TEXTOS LITE- RARIOS DE AUTORES CLÁSICOS}

Este tipo de edicións de autor ían acompañadas, normalmente, dunha especie de estudo introdutorio en que se analizaba a importancia que tiña achegar esa obra aos nosos días, debido, principalmente, ao seu contido ou á persoa que se encontraba detrás da creación do texto. Son obras deste tipo Pelerinaxes I de Ramón Otero Pedrayo, cuxo motivo principal é a viaxe desde Ourense a San Andrés de Teixido que serve para recuperar unha tradición a través dun dos santuarios máis populares e antigos de Galiza e para reflexionar sobre a etnografía, a historia ou a economía do país. Tamén, Beira o Barbaña. Paisaxes de Francisco Álvarez de Nóvoa, cuxa publicación no Castro contribúe á recuperación dun texto pouco coñecido que se centra nunha descrición paisaxística a cal nos remite á nostalxia dun tempo pasado e á imposibilidade de retorno. 
Outra das obras publicadas polo Castro é Os tres poemas premiados en 1877 no certame de Ourense de Manuel Curros Enríquez, que nos achega, como sabemos, a produción dun dos homes máis importantes do Rexurdimento galego. Do mesmo autor é a obra Eduardo Chao, que rescata do esquecemento a un home importante para a historia de Galicia pola súa loita continua co obxectivo de conquistar as liberdades e os dereitos democráticos dun país. Algo semellante ocorre con Os calaicos. Odas a Anacreonte de Florencio Vaamonde, veciño do Castro tamén esquecido, a quen Díaz Pardo lle quere render homenaxe pola achega que as súas obras supoñen para a cultura galega. Por último, situamos dentro deste grupo a $\mathrm{Ar}$ lequinada de Torcuato Ulloa Varela, onde se recollen unha serie de artigos cómicos publicados por primeira vez en 1894 e que o Castro recupera nos seus últimos anos de produción.

\subsection{MATERIAIS CIENTÍFICOS DE VALOR HISTÓRICO}

Entre a produción do Castro, encontramos unha serie de documentos de carácter científico que contan cun importante valor histórico. Son, na maioría dos casos, publicacións que contribúen á recuperación da historia e da actividade desenvolvida na Galiza nos anos precedentes á guerra, entre os que se encontran temáticas diferentes como as seguintes:

Historia. Este tema é o que ten unha maior presenza en Ediciós do Castro posto que un dos obxectivos principais da editora era recuperar aqueles feitos e personaxes que formaban parte do pasado da Galiza. Pertencen a este grupo obras cuxa publicación orixinal aparece antes do século XX, como é o caso de Compendio de Albeytería de Fernando de Sande, que nos achega un dos primeiros estudos sobre as Ciencias Naturais en que posteriormente se baseará o Padre Feijoo. Outro exemplo é a Descripción geonóstica del Reino de Galicia de Guillermo Schulz, cuxo traballo se centra na estrutura da composición das rochas que forman o territorio galego. Existen, ademais, outros textos de carácter histórico que aparecen nos primeiros anos do século XX como Historia del periodismo santiagués de Pablo Pérez Constanti, La universidad de
Santiago. El pasado y el presente de Ciriaco Pérez Bustamante e Sebastián González García-Paz e o Corpus petroglyphorum gallaecia de Ramón Sobrino Buhigas. O primeiro deles trata o tema da prensa compostelá e galega do século pasado que debeu ser tida en conta para a creación, en anos posteriores, de diferentes xornais en Compostela; na obra sobre a Universidade de Santiago encontramos a importancia que se lle concede ao patrimonio histórico e, na de Sobrino Buhigas, recóllense unha serie de petróglifos que forman parte do pasado de Galiza. Entre as reproducións facsimilares, tamén podemos falar de Prisión Central. Celanova (1939-1940), que contén un álbum dos presos políticos deses anos na cidade ourensá e que nos remite á mesma liña seguida pola colección Documentos.

Economía. Hai unha serie de publicacións que teñen como liña principal o tratamento de diversos aspectos de carácter económico. Neste grupo encontramos, primeiramente, as reproducións facsimilares de dous congresos: Congreso agrícola gallego e Primer congreso de economía gallego, que recollen feitos decisivos na configuración da sociedade galega baseados na necesidade de reformar a agricultura e de crear novas propostas para o desenvolvemento económico de Galiza. No primeiro dos casos, a reedición débese, así mesmo, a unha homenaxe aos seus promotores, mentres que no segundo o obxectivo é dar a coñecer aspectos que xa foron superados para que na actualidade non se repitan. En relación a isto, aparecen as obras Memoria sobre el conocimiento de las tierras de Francisco Cónsul Jove i Tineo e Reformas que se pueden implantar en Galicia para el progreso de la agricultura de Juan Rof Cordina, que explican como cultivar as terras nas circunstancias en que se encontra Galiza e mostran, como no caso dos congresos, unha preocupación pola necesidade da reforma agrícola en relación á súa organización e á súa técnica. Outro exemplo é o Ensayo de una historia de los peces onde se trata o tema da pesca, descoñecido na Galiza daquel tempo (1788), e que ten relación, por outro lado, co ámbito das Ciencias Naturais, que comentaremos máis adiante. Ademais, o interese desta reprodución aparece na recuperación do pensamento do seu autor, Joseph A. 
Cornide Saavedra, que foi un dos membros máis coñecidos durante a Ilustración galega.

Ciencias Naturais. No referente aos materiais de carácter científico, que se supón que contan cun importante valor histórico para Galiza, podemos encontrar un grupo de publicacións que serven para a amplificación do discurso científico moderno. A obra máis antiga que se reproduce é a Reseña de la historia natural de Galicia de Víctor López Seoane, quen desenvolve unha ampla actividade de recolleitas e pescudas relacionadas coa fauna e a flora galega, ignorada durante moito tempo. O Castro recolle por primeira vez Viajes de herborización por Galicia ${ }^{7}$, que pasa a ser unha das principais realizacións na taxonomía galega a nivel do que se facía nos estudios científicos internacionais e a raíz da cal xorde unha comunidade científica galega dentro das Ciencias Naturais. Outras obras deste tipo son Enumeración de los curculiónidos de la Peníncula Ibérica e Islas Baleares, de Luís Iglesias Iglesias, que nos remite aos traballos levados a cabo polo Seminario de Estudos Galegos, e o Curso práctico de apicultura de Benigno Ledo González, que destacou polo seu amplo interese e importante número de ventas entre a sociedade galega.

Xeografía, antropoloxía e etnografía. Como é sabido, durante a época de preguerra destaca o labor levado a cabo polo grupo Nós e polo Seminario de Estudos Galegos que estudaban e divulgaban o patrimonio cultural da Galiza. Nesta liña, a editorial de Díaz Pardo publica un gran número de textos cuxa primeira edición aparece en mans destas agrupacións, entre os que encontramos obras como Santa Marta de Moreiras de Xosé Ramón e Fernández Oxea, Terra de Melide do Seminario de Estudos Galegos ou Cuaderno de campo de Guillermo Schulz, a través das cales podemos ver cal era o espírito e o funcionamento das citadas organizacións galeguistas ${ }^{8}$. No caso das dúas primeiras publicacións, faise referencia ao estudo histórico, cultural e artístico de dúas localidades como son a parroquia de $\mathrm{Ou}-$ rense e a vila de Melide, mentres que na obra de Schulz se recollen unha serie de manuscritos do autor nos que se relata unha visita frustrada ao Monte Pindo. Ademais destas, existen outras obras nas que tamén aparece o carácter recuperador dunhas ideas ou pensamentos previos á guerra civil como Grabados en linoleum, Pelegrinaxes I, Corpus petroglyphorum gallaeciae e unha serie de textos divulgativos que veremos posteriormente.

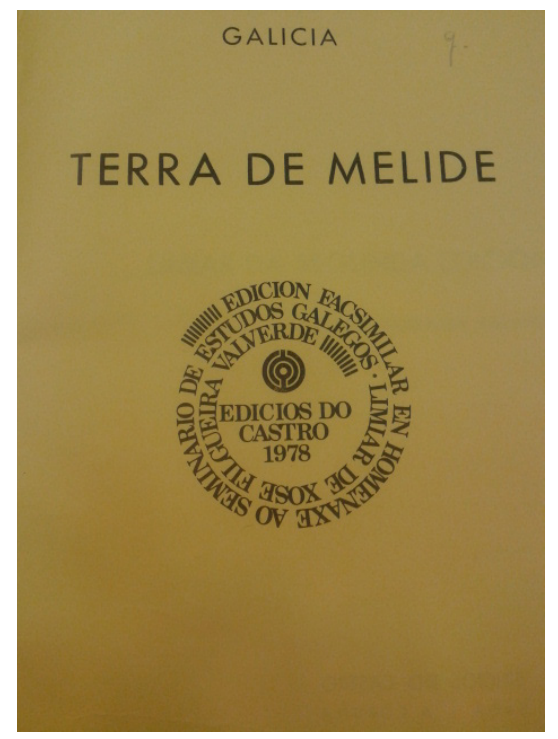

Interdisciplinares. No catálogo de obras de Ediciós do Castro podemos diferenciar dúas pezas que teñen un carácter interdisciplinar posto que combinan diferentes liñas como a historia ou o debuxo. Este é o caso de materiais como Grabados en linoleum de Xaime Prada e de Homenaje a la Torre de Hércules de Luís Seoane. O primeiro é, ao tempo, unha das obras publicadas en Nós cuxa edición facsimilar nos achega a un momento anterior á guerra

\footnotetext{
${ }^{7}$ Trátase dunha edición facsimilar da revista Razón y Fe redixida polos Padres da Compañía de Jesús.

${ }^{8}$ As obras de Cuaderno de campo e Terra de Melide están recollidas na colección das Publicacións do Seminario de Estudos Galegos que realiza o Castro. Esta colección foise constituíndo a medida que se ían creando as diversas áreas do novo Seminario de Estudos Galegos (1978) que pretende traer ao presente as ideas do vello Seminario, disolto durante a Guerra Civil.
} 
en que os estudos e o fortalecemento da cultura galega ocupaban un lugar central. No referente á obra de Seoane, a súa aparición prodúcese cando o centro de produción literaria e cultural xa está en América, onde encontramos moitas das obras deste autor exiliado que desenvolveu un papel cultural moi destacado, non só pola súa produción artística ou literaria, senón tamén a través do seu labor como editor, colaborador en xornais e revistas etc.

Publicacións periódicas. Malia que a maioría das publicacións recollidas son libros, existen determinados xornais e revistas que aparecen no corpus de análise. No primeiro dos casos, recóllense integramente dous dos xornais feitos na Galiza de principios de século: El barbero municipal (1910-1914) e o Galicia. Diario de Vigo (1922-1925), que serven como mostra da historia vivida nos inicios do século XX. El barbero Municipal utilízase como voceiro dunha loita local contra os caciques e tiña como principal colaborador a Castelao, quen tamén participa posteriormente en Galicia, xornal de carácter galeguista, liberal e independente, dirixido por Paz Andrade que consegue sobrevivir á ditadura de Primo de Rivera, pese a estar ameazado polas continuas críticas políticas que estaba a facer.

No referente ás revistas, temos que diferenciar entre as reproducións das publicacións previas á guerra civil, as que se corresponden cos anos da contenda e as que son posteriores a ela. En relación ás anteriores á guerra, aparece a publicación P.A.N Revista epistolar $y$ de ensayo que nacera en 1935, derivada das conversas dos homes que se xuntaban nos parladoiros da capital entre os que se encontran Eduardo e Rafael Dieste, Eugenio Fernández Granell, Blanco Torres, Lorenzo Varela ou Cándido Fernández Mazas, todos eles cun grande compromiso coa liberdade e coa causa republicana. Durante os anos da guerra continúan saíndo á luz publicacións periódicas como é o caso da revista Nova Galiza, que foi editada en Barcelona e publicada cada dous meses entre 1937 e 1938 . Conta cun total de dezaoito números que, no inicio, se repartían aos soldados galegos do exército republicano, e os seus colaboradores principais, entre os que se encontraban Basilio Álvarez, Eduardo Blanco Amor, Ramón Cabanillas, Arturo Cuadrado ou Luís Seoane, que na súa maioría, estiveron no exilio. Á súa vez, en 1937 aparece en Madrid a revista Nueva Galicia que actúa como voceiro dos antifascistas galegos onde, máis unha vez, achamos a presenza de Castelao. Esta publicación sufriu as consecuencias derivadas da guerra civil e tivo que trasladarse a Barcelona para seguir publicando. Tras a guerra, e como comentamos en apartados anteriores, practicamente a totalidade das publicacións trasládanse a América onde aparecen Correo Literario e Galicia emigrante, ambas centradas na Galiza e nos galegos.

\subsection{OUTRAS PUBLICACIÓNS FACSIMI- LARES}

Para alén do dito até o de agora, existe outra serie de obras que se reproduciron no Castro e que resulta difícil incluír dentro das liñas temáticas anteriores. Este é o caso da Declaración universal do dereitos do home, cuxo tema resulta de grande interese social, e de Ritmo y abstración y los procesos abstractivos del arte contemporáneo ${ }^{9}$ de Tomás Barros, onde se reproduce de forma parcial a obra deste autor.

\section{VALORACIÓNS E CONCLUSIÓNS}

Tras estudarmos cales son as obras facsimilares de Ediciós do Castro e analizarmos como eran as súas correspondentes orixinais podemos extraer diferentes valoracións. En primeiro lugar, podemos afirmar que estes materiais responden á continuación coa liña de fondo da editorial levada a cabo por Díaz Pardo, consistente na recuperación dun conxunto de pezas que forman parte do pasado dun pobo. Se temos en conta a análise cronolóxica

\footnotetext{
${ }^{9}$ Esta obra non é completamente facsimilar mais si o é unha parte dela polo que consideramos adecuado incluíla aquí, aínda que as súas características e o seu interese non vaian na liña do comentado anteriormente.
} 
que fixemos dos textos, observamos como se reproducen escritos de diferentes séculos, o cal deixa ver un interese por parte da editorial nuns materiais concretos que sirvan para a reconstrución dun pasado que parecía esquecido ou mesmo descoñecido. No referente aos materiais orixinais que se recollen, resulta relevante o marco da situación en que teñen lugar, xa que encontramos que a editora selecciona textos de carácter histórico ou de discurso científico pertencentes aos séculos XIX e anteriores, textos derivados das ideas do grupo Nós e o Seminario de Estudos Galegos que se corresponden cos anos previos á guerra e materiais con referencias a ela que apareceron durante a ditadura. Tamén temos que nos referir a aquelas publicacións realizadas en América, que deixan ver a situación que se estaba a vivir durante a primeira metade de século, a través dos intelectuais que, en moitas ocasións, se viron na obriga de marchar ao exilio para poder gozar das liberdades que por aquel entón aquí non existían.

Por outro lado, para contribuír a esta liña editorial da que estamos a falar, o Castro pon o foco nuns temas concretos como son, entre outros, o exilio, a loita antifranquista ou os materiais científicos, que teñen un importante valor histórico e que chegan a nós a través de diferentes textos relacionados non só coa historia, senón tamén coa economía, a etnografía, a xeografía, as ciencias naturais etc. Este conxunto de obras reproducen documentos cuxo coñecemento está novamente relacionado coa análise da memoria do noso pasado e que resulta moi relevante pola contribución que fai, entre outras cousas, ao estudo científico nun momento en que non se dispuña de traballos sobre o tema. Existe, así mesmo, por parte da editorial, unha clara vontade de volver publicar aqueles textos previos á guerra nos que se amosan temas e intereses que teñen a ver cos defendidos polas organizacións e institucións galeguistas de principios de século. Tamén, a recuperación dos autores clásicos por parte de Ediciós do Castro resultou imprescindíbel no que á conformación do sistema literario galego se refire, así como, o interese e a preocupación que desde o principio existiu polos aspectos artísticos e que vemos a través da publicación de diferentes gravados, de ilustracións no interior das obras, das capas etc. Do mesmo modo, a existencia de publicacións periódicas, como as revistas ou os xornais, contribúen a un maior coñecemento dunha época e dun pobo, tendo en conta aqueles materiais que se publicaban e distribuían entre a sociedade.

É preciso, tamén, facer referencia a aqueles lugares de publicación e a aquelas editoriais nas que aparecen por primeira vez as pezas que recolle o Castro, xa que contribúen á creación da historia, marcada pola necesidade de dar saída aos textos nas principais editoras, xa non do país, senón de España ou de América. A través do Castro podemos coñecer as organizacións que se encargaban de difundir os diferentes materiais e aquelas cidades nas que se encontraban as principais casas editoriais de cada momento.

Non debemos rematar a nosa análise sen dicir que o Castro non é a única editora que conta con edicións facsimilares feitas a finais do século XX; tamén o fan outras como é o caso de Galaxia ${ }^{10}$, Monterrey ${ }^{11}$ ou Alvarellos. Aínda que non fixemos unha análise exhaustiva das producións facsimilares destas editoriais, podemos dicir que no caso desta última, por exemplo, existen uns facsimilares que se ocupan de recuperar unha serie de textos históricos do século XVII. A liña utilizada é diferente á de Díaz Pardo posto que, mentres este ten unha vontade explícita de nos achegar a historia dun pobo, Alvarellos o que recolle son materiais que resultaron de certa importancia polo seu carácter erudito e que están

\footnotetext{
${ }^{10}$ Edita en forma facsimilar, por exemplo, obras como Os vellos non deben de namorarse (2000) de Castelao, As cruces de pedra na Galiza (1984) tamén de Castelao ou Arredor de si (2007) de Otero Pedrayo.

${ }^{11}$ Edita en facsímil obras como o Entremés famoso sobre a pesca no río Miño (1953) de Gabriel Feixoo de Araúxo.
} 
relacionados, entre outros asuntos, coa historia de España ou da Galiza ${ }^{12}$.

A modo de conclusión, podemos afirmar que as edicións facsimilares do Castro o que fan é dar voz aos escritores do exilio, reproducir revistas e xornais que nos achegan a mentalidade e a situación pola que estaba pasando a nosa sociedade, recuperar temas que no seu día foran censurados, recoller o coñecemento científico xa estudado para poder ampliar con iso o seu discurso moderno, volver aos clásicos... e deixar claro, desta maneira, importancia de achegar ao presente unha memoria histórica que durante moitos anos resultou descoñecida ou estivo esquecida.

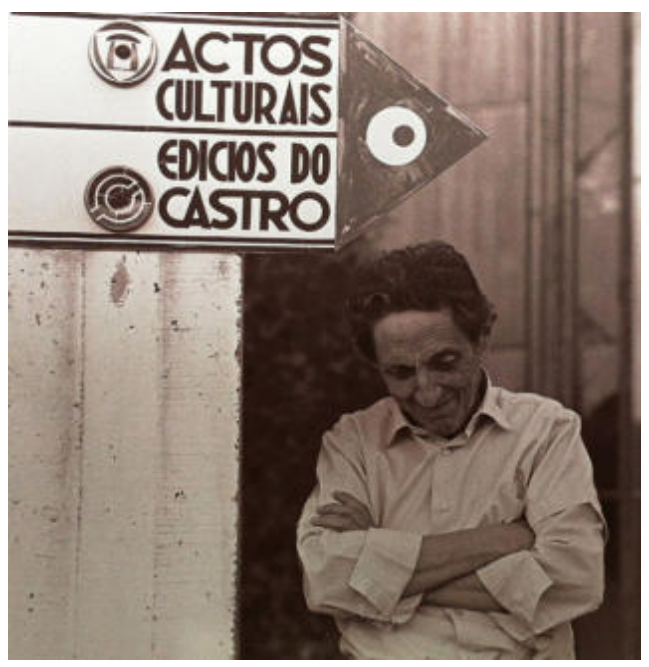

\section{REFERENCIAS BIBLIOGRÁFICAS}

Alonso Montero, Xesús (2012): "Isaac Díaz Pardo, colaborador intelectual y económico de la editorial antifranquista Ruedo Ibérico", Laberintos. Revista de estudios sobre los exilios culturales españoles 14 , pp. 317-322.

Catálogo Ediciós do Castro (2007). Sada: Ediciós do Castro.

Cores Trasmonte, Baldomero (1981): La sociedad incompleta. El drama de la capitalidad de Galicia. Sada: Ediciós do Castro

Díaz Arias de Castro, Xosé e Guillermo Escrigas (eds.) (2006): Isaac Díaz Pardo: creación e compromiso na Galicia do século XX. A Coruña: Deputación Provincial.

Díaz Pardo, Isaac (2009): “Como coñecín a Luís Seoane”, Galegos = Gallegos 7, pp. 74-76.

DíAz, Xosé (coord.) (2008): Sargadelos recuperado. O Laboratorio de Formas 40 anos despois. A Coruña: Fundación Luís Seoane.

(2010): "Seoane, o deseño e o Laboratorio de Formas de Galicia", Raigame: Revista de Arte, Cultura e tradicións populares 33, pp. 34-41.

Fandiño Veiga, Xosé Ramón (2008): Isaac Díaz Pardo. A patria enteira na memoria. Vigo: Ir Indo.

FAndiño, Xosé Ramón (2012): A luminosa mirada dos ollos de Isaac. Isaac Díaz Pardo. Obra dispersa. Santiago de Compostela: Xunta de Galicia.

Freixanes, Víctor F. (2003): “Isaac Díaz Pardo: Non hai futuro sen memoria”, Dez Eme: Revista de Historia e Ciencias sociais da fundación 10 de marzo 6, pp. 70-77.

Laboratorio de Formas de Galicia (1970). Sada: Ediciós do Castro.

MARIÑo, Luís (1990): “Isaac Díaz Pardo, editor”, Isaac Díaz Pardo. Un proxecto socio-cultural para Galicia. Santiago de Compostela: Auditorio de Galicia.

Soneira Beloso, Begoña (2007): Unha ollada ó laboratorio de Formas os 44 anos da súa creación. Sada: Ediciós do Castro.

\footnotetext{
${ }^{12}$ Exemplos destas obras son: España Sagrada de Henrique Flórez, Historia de Galicia de Benito Vicetto ou Obras del cura de Fruíme de Diego Antonio Cernadas y Castro.
} 